\title{
Danza mediatizada al servicio de la ideología en las fiestas y los actos propagandísticos celebrados en Sevilla durante la guerra civil española*
}

\author{
DANCE MEDIATIZED AT THE SERVICE OF IDEOLOGY DURING THE FESTIVITIES \\ AND PROPAGANDA EVENTS HELD IN SEVILLE DURING THE SPANISH CIVIL WAR
}

DANÇA MEDIATIZADA AO SERVIÇO DA IDEOLOGIA NAS FESTAS E NOS ATOS

PROPAGANDÍSTICOS CELEBRADOS EM SEVILLA DURANTE A GUERRA CIVIL ESPANHOLA

\section{Ana María Díaz Olaya**}

Cuadernos de Música, Artes Visuales y Artes Escénicas

/ Volumen 13- Número 2 / Julio - Diciembre de 2018

/ ISSN 1794-6670/ Bogotá, D.C., Colombia / pp. 97-121

Fecha de recepción: 11 de enero de 2018

Fecha de aceptación: 1 de abril de 2018

Disponible en línea: 6 de julio de 2018

doi 10.11144/javeriana.mavae13-2.dmas

* Artículo de investigación. Resultado del proyecto de investigación I+D Danza durante la Guerra Civil y el franquismo (1936-1960): políticas culturales, identidad, género y patrimonio coreográfico. HAR2013-48658-C2-2-P (Ministerio de Economía y Competitividad. Programa Estatal de Fomento de la Investigación Científica y Técnica de Excelencia). Investigadora principal: Beatriz Martínez del Fresno. La autora de este capítulo forma parte del equipo investigador de dicho proyecto.

* Licenciada en Historia y Ciencias de la Música por la Universidad de Granada y doctora en Historia y Ciencias de la Música por la Universidad de Málaga. Profesora Titular del área de Didáctica de la Expresión Musical, del Departamento de las Lenguas, las Artes y el Deporte, y directora académica del título de Experto Universitario en Estudios Flamencos y cursos de extensión universitaria en Flamenco de la Cátedra de Flamencología de la Universidad de Málaga. ORCID: 0000-0002-0735-3111 


\section{Resumen}

Este trabajo se encuentra enclavado dentro de la temática relacionada con los esfuerzos propagandísticos del levantamiento franquista y la dictadura a través de la mediatización de las artes. En este caso concreto, está centrado en la danza y su desarrollo en un enclave que fue representativo durante la guerra civil, la ciudad de Sevilla, testigo de las principales fiestas y actos propagandísticos que se llevaron a cabo dentro de la España nacional. Inmersos en este ambiente, se ha pretendido analizar la frecuencia y el modo en que la danza tomó parte de este tipo de eventos como herramienta propagandística, así como su posible similitud con la danza de posguerra en cuanto a su participación como elemento clave del discurso político-propagandístico trazado por el franquismo. Para estos fines, se ha realizado un extenso recorrido a través de bibliografía específica, los principales diarios de la época y las diversas fuentes de archivo conservadas, percibiéndose tanto la utilización propagandística estratégica de este arte coreográfico como su protagonismo en cuanto a la definición y concreción de lo que sería la danza bélica y posbélica española característica del bando franquista.

Palabras clave: Sevilla; guerra civil; danza; propaganda; mediatización

\section{Abstract}

This work is embedded in the subject related to the propaganda efforts of Franco's uprising and dictatorship through the mediatization of the arts. In this specific case, it is centered on dance and its development in an enclave that was representative during the civil war, the city of Seville, witness to the main festivals and propaganda events that took place within national Spain. Immersed in this environment, the purpose has been to analyze the frequency and the way in which dance took part in this type of events as a propagandistic tool, as well as its possible similarity with the postwar dance in terms of its participation as a key element of political-propagandistic discourse traced by Francoism. For these purposes, an extensive review has been made of specific bibliography, the main newspapers of the time, and the diverse sources of archives conserved, perceiving both the strategic propagandistic use of this choreographic art and its leading role in terms of definition and concretion of what would be the Spanish war and post-war characteristic dance of Franco's side.

Keywords: Sevilla; civil war; dance; propaganda; mediatization.

\section{Resumo}

Este trabalho está situado dentro da temática relacionada com os esforços propagandísticos do levantamento franquista e a ditadura através da midiatização das artes. Neste caso concreto, está centrado na dança e seu desenvolvimento em um enclave que foi representativo durante a guerra civil, a cidade de Sevilla, testemunha das principais festas e atos propagandísticos realizados dentro da Espanha nacional. Imersos neste ambiente, pretende-se analisar a frequência e o modo em que a dança tomou parte deste tipo de eventos como ferramenta propagandística, assim como a sua possível semelhança com a dança de pós-guerra em quanto a sua participação como elemento chave do discurso político-propagandístico traçado pelo franquismo. Para estes fins, tem se realizado um extenso recorrido a través de bibliografia específica, os principais diários da época e as diversas fontes de arquivo conservadas, percebendo-se tanto a utilização propagandística estratégica desta arte coreográfica como seu protagonismo em quanto à definição concreção do que seria a dança bélica e pós-bélica espanhola característica do bando franquista

Palavras chave: Sevilla; guerra civil; dança; propaganda; midiatização. 


\section{INTRODUCCIÓN}

Todo intento de consolidación de un régimen dictatorial conlleva una persistente búsqueda de legitimidad a través de ciertos mecanismos basados en procesos de sociabilización sobre las creencias y los comportamientos que este pretende imponer. En el caso de la guerra civil española, entendida como antecedente de una dictadura que acapararía cuatro décadas de la historia de este país, entre las estrategias que los nacionales utilizaron para lograr derrocar al bando republicano y, a su vez, ensalzar la grandeza de la España que estaba por venir, se contempla de forma eminente el hecho propagandístico, destinado, fundamentalmente, a servir a los intereses bélicos de la contienda y al nuevo Estado que se estaba gestando. Si bien es cierto que al comienzo de la guerra los sublevados no le concedieron tal importancia, en poco tiempo lograron estructurar un grandioso engranaje propagandístico que les conduciría al éxito final.

Dado el cariz de esta investigación, es de gran utilidad la aproximación que realiza Pérez Zalduondo (2013) a este hecho propagandístico desde una perspectiva artística general. Con respecto al papel concreto de la danza y su acción propagandística durante esta época, existen contadas referencias (Murga 2009). Sin embargo, nos encontramos una mayor profundización respecto de este arte coreográfico en la posguerra gracias a los estudios realizados por Martínez del Fresno (2010, 2012, 2013 y 2015) y Casero García (2011) que nos conducen, por una parte, a mantener una idea clara sobre la utilización de esta disciplina en el periodo posbélico y, por otra, a establecer ciertos paralelismos con el uso que se le dio en la contienda.

En cuanto al desarrollo cultural de los emplazamientos de retaguardia durante la guerra civil española, diversas investigaciones nos permiten acceder a la manera de vivir del pueblo al otro lado del frente, con frecuencia sumergido en un mundo irreal gracias al constante deleite terrenal de los sentidos a través de los placeres culturales y mundanos que ofrecía la cultura local (Abella 1975; Escolar 1987; Fernández 2015; I Iglesias 2013; Martínez del Fresno 2010; Pizarroso 2002; Rodríguez 2003; Ruiz 1993; Sevillano 2014). Las citadas investigaciones, de las que se puede deducir que las disciplinas artísticas ocuparon un rol fundamental dentro del elemento propagandístico de los dos bandos enfrentados, han sido realizadas desde una perspectiva poliédrica y están referidas mayoritariamente a ciudades de ideología republicana.

Sevilla, ciudad de retaguardia, fue testigo desde el inicio del conflicto de numerosas celebraciones donde un despliegue de medios nada desdeñable las convertía en símbolos del poder y superioridad del bando nacionalista. Estas manifestaciones festivas, en las que con gran asiduidad el arte coreográfico ocupaba un espacio propio, poseían un claro componente propagandístico acorde con la fuerte carga ideológica que se pretendía establecer y estaban destinadas a encumbrar a la figura del caudillo, así como conseguir la anhelada victoria. La maquinaria puesta en marcha en cada una de ellas resultaba demoledora y no escatimaba en recursos, sobre todo, en las visitas de personalidades; la capital andaluza debía dar imagen de fortaleza económica y moral como representación de la urbe nacional por autonomasia, bien ante otras poblaciones aún en manos del bando republicano, bien hacia los países que ofrecían su apoyo a Francisco Franco.

La mayoría de las investigaciones locales desarrolladas en este periodo, principalmente por Langa Nuño (2000, 2007a y 2007b), se centran en analizar aspectos políticos y sociales. Sin embargo, con referencia a la cultura en general y a la danza en particular, no existen publicaciones como tal, tan solo escasas referencias relacionadas con su inclusión en el ambiente nocturno de la ciudad (Abella 1975; Rodríguez 2003). 
Para poder reconstruir esta escena concreta, la pertinente consulta bibliográfica relacionada con el tema se ha complementado con un exhaustivo vaciado de prensa de los diarios sevillanos. Este análisis hemerográfico ha resultado un arduo trabajo como consecuencia de los procedimientos empleados por parte del bando nacional: explotación de sentimientos a través de la simplificación, tergiversación y desvirtuación de la información con el fin de lograr una manipulación de las actitudes y conductas de la ciudadanía (Sevillano 2003). Por una parte, se muestran en demasía los actos benéficos y patrióticos, procediéndose, en ocasiones, a exagerar cifras de asistentes o participantes. Los primeros se describen detalladamente con cierto matiz victimista que, sin duda, procuraba movilizar el sentimiento ciudadano a favor del bando franquista. Los segundos aparecen diariamente anunciados antes y después del evento, incluso en varias páginas de un mismo diario. Claramente, se buscaba promover el espíritu nacional hacia la implantación de esa nueva ideología ultracatólica que se pretendía imponer a toda costa. Por el contrario, la omisión de información se hace patente en actos o eventos que no pudieran conseguir un efecto positivo en cuanto a la consecución de la victoria. Estos se referían, según se ha podido constatar, a acciones graves contra el bando republicano o, en relación con nuestro objeto de estudio, a la danza silenciada de la cual se hablará en líneas posteriores. Por otra parte, la tergiversación de la información es más que evidente en noticias acerca de los actos impuros, crueles y obscenos originados por el bando contrario frente a la bonanza del propio bando. Ante esta situación y con idea de poder contrastar esta dudosa información hemerográfica y llevar a cabo el proceso investigador con el rigor necesario, se ha procedido a la revisión y recopilación de testimonios complementarios procedentes de las fuentes de archivo existentes y de diversos diarios republicanos.

Gracias a la información obtenida, se ha logrado, por una parte, realizar un recorrido en torno al desempeño propagandístico de la danza en la ciudad a través de su utilización cotidiana en las fiestas y celebraciones como herramienta ideológica destinada a consolidar las identidades nacionales y regionales impuestas a partir del golpe de Estado. Asimismo, como nuestro estudio se centra en un emplazamiento nacional modelo donde se llevaron a cabo todo tipo de "experimentos" de lo que supondría la nueva nación, se ha establecido como objetivo secundario averiguar la existencia de similitudes entre el empleo de la danza bélica sevillana y la danza de la posguerra española, atendiendo a cuestiones como su rol propagandístico dentro del bando sublevado o su feminización, al otorgar, principalmente, a la mujer la responsabilidad en cuanto a su desarrollo y puesta en escena, pero siempre bajo condicionantes varoniles.

Es necesario aclarar el encuadre de este artículo como un estudio de caso de tipo histórico basado en el análisis, la descripción y la interpretación de los hechos acontecidos en Sevilla, enclavado dentro de la temática relacionada con las artes y los esfuerzos propagandísticos del levantamiento franquista y la dictadura. En ningún caso, aunque se hayan realizado ciertas referencias a estos aspectos a lo largo del trabajo, se ha pretendido abordar desde un enfoque antropológico en torno al fascismo, el cuerpo y la sexualidad, desde un punto de vista local, nacional o internacional.

En cuanto al desarrollo del cuerpo argumental propuesto, centrado en la "danza mostrada" u oficial, se realizará un primer acercamiento alrededor del ambiente social y festivo sevillano y las tipologías de danza que predominaban en la ciudad durante este periodo histórico. 


\section{FIESTAS Y ACTOS PROPAGANDÍSTICOS CELEBRADOS EN SEVILLA}

Durante el transcurso de la contienda, cualquier medio de propaganda se consideraba válido si con ello se inducía a la consecución de la esperada victoria en uno u otro bando. El ejemplo de Sevilla no fue una excepción en cuanto a la utilización de todos los artilugios persuasorios al alcance de los nacionales. Por su posición geográfica estratégica y su condición de plataforma para que el ejército sublevado lograra convertir el golpe de Estado fallido en una guerra civil, resultó ser un enclave fundamental de retaguardia a lo largo del conflicto. Reconocido centro económico de primera magnitud, se utilizó como escaparate de la grandeza de la España nacional, llegando a ser considerado un referente gracias a las diversas acciones sociales inteligentemente desarrolladas por el general Gonzalo Queipo de Llano, entonces máxima autoridad. Pero, sin lugar a dudas, el efecto decisivo ante su omnipotencia con respecto a otras ciudades españolas lo alcanzó gracias a fiestas, funciones benéficas, concentraciones multitudinarias, visitas de personalidades o mandatarios de países aliados y del territorio liberado y celebraciones en honor de estos países que allí se llevaban a cabo. Con esta imagen de ciudad ejemplar, se pretendía ganar adeptos de la zona republicana, convencer a los desafectados del propio bando o bien buscar apoyo extranjero (Langa 2007a, 450). Para ello, la propaganda fue empleada de manera estratégica como complemento a la violencia que, por otra parte, se estaba generando en el campo de batalla y así contribuyó a la búsqueda de legitimidad tanto en la consolidación de una guerra infundada como en el panorama político que se pretendía instaurar.

La organización de la mayoría de estos actos contaba con la participación del general Queipo de Llano y de las diferentes corporaciones locales, como era el caso de las funciones benéficas y las que se hacían en honor de los países aliados. En cuanto a las visitas de autoridades, las concentraciones multitudinarias y la celebración de fiestas, el Gobierno Civil y el Ayuntamiento asumían la responsabilidad, contando en determinadas ocasiones con la colaboración de la Falange Española Tradicionalista (FET) o de alguna otra entidad benéfica o social; el primero notificaba acerca de las diferentes visitas y festividades por celebrar al segundo y este se encargaba de organizar hasta el más mínimo detalle. Como se refleja en los documentos de archivo, el alcalde presentaba en las diferentes sesiones de Pleno a la Comisión Gestora la propuesta de celebración de cualquier evento. Dicha comisión, a través de los Negociados de Ferias y Festejos y Asuntos Especiales de la Secretaría General, era la encargada de aprobar el presupuesto y los detalles de este añadiendo a lo referido la infraestructura necesaria, organizando las diversas actividades previstas, preparando los contratos de los artistas participantes y redactando las pertinentes notas de prensa destinadas a los diarios locales.

A partir de 1938, coincidiendo con la formación del Primer Gobierno Regular de Franco y la asignación oficial por parte del caudillo de una misión propagandística a la Falange Española Tradicionalista y de las Juntas de Ofensiva Nacional Sindicalista (FET y de las JONS) con su consecuente subordinación y estatalización (Sevillano 2003, 39), se observa un mayor protagonismo de este partido en la preparación de toda clase de conmemoraciones oficiales. Sin embargo, este quehacer no se limitaría al citado año, sino que, desde el comienzo de la contienda, quedaría patente gracias a la planificación de funciones benéficas en un intento de acaparar la máxima popularidad posible. A pesar de la imagen de unidad que se pretendía 
ofrecer públicamente en la organización de tales eventos, la realidad es que se produjeron continuas luchas de poder entre los diferentes estamentos políticos, como se puede dilucidar a partir del siguiente expediente referido al lugar que en los actos oficiales debía ocupar el jefe provincial de la FET de las JONS:

Debo manifestar a VE que en los actos oficiales las Autoridades o sean Gobernadores Militares y Civiles, autoridades de la Marina, Presidente de la Audiencia y Alcalde deben tener preferencia de lugar sobre el Delegado Provincial de FET de las JONS. (Archivo Municipal 1937e) ${ }^{1}$

En cuestión económica, cada festejo de este calibre suponía un auténtico derroche si se tienen en cuenta las penurias que estaba padeciendo la población, a la que se acallaba mediante mecanismos propagandísticos de Auxilio Social, cocinas económicas, días de plato único, recolecta de abrigos y juguetes y alguna que otra función benéfica. Dignas de mención resultan las Fiestas de Triana celebradas los días 24, 25 y 26 de julio de 1936, tan solo dos días después de que se informara a través de la prensa de la destrucción de Triana y San Julián, barrios resistentes al poder nacional por su rebeldía criminal marxista. Aun así, se llevaron a cabo "grandes fiestas Populares, fuegos artificiales, cucañas acuáticas, deportes en general: Grandes retretas militares y conciertos por la Banda Municipal" (Archivo Municipal 1936a). Escasos días después, se impulsó una función en honor de la Festividad de la Virgen de los Reyes a beneficio de las familias obreras damnificadas de estos barrios, organizada por los mandos de la FET de las JONS y a la que asistieron altas autoridades militares y civiles, entre ellas, Queipo de Llano y el gobernador civil de entonces, Pedro Parias ( $A B C, 14$ de agosto de 1936; $A B C, 16$ de agosto de 1936). Con este tipo de actuaciones tras la masacre de un pueblo inocente y la práctica total devastación de unos enclaves tan emblemáticos, el bando nacional intentaba compensar el terrorismo ejercido mediante fiestas y actos benéficos con el fin de lavar su imagen.

Otro ejemplo de derroche económico lo encontramos en la visita del Sultán Azul a la ciudad en agosto de 1937, a la que se destinó por parte del Negociado de Asuntos Especiales un presupuesto de 20000 pesetas (Archivo Municipal 1937d). Pero todo esfuerzo suponía una recompensa posterior. En realidad, Franco no anhelaba el apoyo del pueblo, sino que utilizaba a la gente de a pie para realizar el trabajo grueso de esta guerra luchando en el frente o procreando para la causa nacional, realizando tareas de acción social o asistiendo como público a cualquiera de las celebraciones que se planificaban. La logística del caudillo iba más allá de mimar y proteger a sus ciudadanos, una acción secundaria si se compara con su afán de formar parte, de manera igualitaria, del círculo de las grandes potencias fascistas, como eran Alemania, Portugal e Italia, y dejar de ser considerado por Adolf Hitler, Benito Mussolini y António de Oliveira Salazar un peón en el juego. Este complejo de inferioridad supone la razón de tales atrocidades económicas para demostrar a sus homónimos la altura de su poder, aun a sabiendas de que esas cantidades justamente destinadas a paliar las desigualdades sociales hubieran aliviado de uno u otro modo la subsistencia de la población civil. Para evitar esta sospecha, el mensaje que se dispensaba al pueblo de forma continuada a través de la prensa (la cual no hacía mención alguna al aspecto económico de estos eventos) referenciaba esta debilidad monetaria, no como resulta del gasto exacerbado por parte de las autoridades, sino debida al estado en el que se hallaba sumido el país como consecuencia de la acción de los republicanos. Si 
se alcanzaba la victoria, esa situación llegaría a su fin, por lo que, en realidad, esta escasez suponía un aliciente para que los españoles adeptos al bando nacional lucharan aún con más ahínco contra el bando contrario. En definitiva, una estrategia más para sembrar el odio hacia la República y dividir aún más a España.

\section{LA DANZA EN SEVILLA DURANTE EL CONFLICTO BÉLICO: DANZA MOSTRADA Y DANZA SILENCIADA}

Conforme las líneas de fuego se iban alejando desde los primeros días de la sublevación militar, la capital hispalense se fue convirtiendo en una ciudad de retaguardia donde solo por vía aérea existía una verdadera amenaza de guerra. Sus habitantes vivían el conflicto, principalmente, a través de la prensa, en tertulias y cafés. Además de su configuración como ciudad cuartel, donde miles de combatientes, heridos y con permiso, residían esporádicamente, su dinamismo económico y político la convertían en una metrópoli para la diversión en la que no escaseaban en su vida cotidiana ofertas de hostelería, restauración y ocio.

La actividad coreográfica adquirió un papel protagonista dentro de esta vida cotidiana, como muestran las continuas y numerosas alusiones aparecidas en los diarios hispalenses. La rápida afiliación de Sevilla a la causa nacional no permitió la permanencia ni el desarrollo de grandes ballets como sucedería en otras capitales españolas, pero sí se detecta la existencia de una danza oficial que se ofrecía al público diariamente, es decir, la "danza mostrada" que se llevaba a cabo en los escenarios de los teatros sevillanos se proyectaba en las salas de cine y se representaba en diversas fiestas y actos propagandísticos donde alcanzaba su máximo cénit como arte al servicio de la propaganda. Sin embargo, antes de adentrarnos en el análisis de esta modalidad, no sería del todo justo excluir de esta cotidianidad coreográfica la danza que se ejecutaba en los locales de ocio y de ambiente nocturno, considerada ociosa y desvirtuada y, por ello, conscientemente ignorada por las principales cabeceras de la época. Las continuas referencias acerca de los eventos públicos donde la "danza mostrada" adquiría protagonismo contrastan con el silenciamiento de este otro tipo de utilización.

Entre la población flotante que acudía diariamente a los enclaves de diversión, se encontraban las comitivas diplomáticas extranjeras que visitaban el país y que eran enviadas a Sevilla por las autoridades nacionales como parte de su periplo turístico. Durante su estancia se les ofrecía todo tipo de espectáculos "oficiosos": flamenco, toros, banquetes y actos patriótico-religiosos (Rodríguez 2003, 147). En horas posteriores, los mismos mandatarios y jerarcas que durante el día visitaban la ciudad y a los que se brindaba todo tipo de agasajos y espectáculos dancísticos oficiales de primer orden presenciaban la danza ofrecida en antros y locales nocturnos:

Hacían sentarse a su lado a las bailarinas andaluzas del establecimiento, y el champán corría a chorros. En honor suyo y renunciando a los tradicionales pasodobles y tangos, la orquesta tocaba valses cada dos por tres, y las señoritas fascistas, presumiendo con sus flamantes revólvers, tenían que cederles la pista. En los pasillos, en los palcos del primer piso, se "divertían" los soldados del Tercio [... . quienes no poseyendo el dinero necesario para ofrecerse champán y señoritas, se entretenían con el espectáculo de las bailarinas desnudas. (Rodríguez 2003, 27) 
Es preciso añadir que esta danza libertina era tan necesaria para el éxito del bando nacional como la danza pública que formaba parte de las fiestas y los actos propagandísticos al asumir un papel fundamental en el descanso, la recuperación y el entretenimiento de la población, además de la propaganda que, en cierta medida, se dispensaba a los turistas sobre la "oferta cultural y social" sevillana. Pero la ciudad debía mantenerse como un referente nacional ante el avance de los sublevados sobre el resto de territorios españoles y precisamente esta forma de expresión artística no suponía una buena representación de lo que debía ser un espectáculo acorde con la ideología ultracatólica que se pretendía instaurar. Sevilla desempeñaba un papel fundamental con respecto al éxito final de la contienda y no podía dejar entrever la vida disipada que se desarrollaba dentro de sus fronteras.

Los estilos de danza interpretados en estos antros (más afines a las costumbres republicanas que a las pertenecientes a la moral conservadora que tendía a inmiscuirse en las mentes de la ciudadanía), las altas horas en que tenían lugar y las posibles reyertas y escenas en las que, con toda seguridad, desembocaban estas actividades, resultaban suficiente motivo para ocultarlas. Además, debe tenerse en cuenta la constante participación femenina, ya fueran las propias bailarinas/bailaoras o las mujeres sevillanas que asistían a ese tipo de diversiones, lo cual suponía la antítesis del nuevo modelo femenino de madre, esposa y asistenta social que se comenzaba a implantar durante el periodo bélico. Aun así, la mujer sevillana no claudicó en ninguno de los intentos que se llevaron a cabo por parte de las autoridades eclesiásticas con el fin de evitar estos ambientes. Para los continuos llamamientos al orden y a la moralización, se utilizó la prensa en repetidas ocasiones. Convencidas las autoridades del fracaso de estos mensajes, se llegó a imponer una orden redactada el 30 de mayo de 1938, cuya finalidad consistía en "dar a la vida pública un tono de digna templanza, de acuerdo a los principios de ascesis religiosa y militar" (Abella 1975, 233).

\section{DANZA MOSTRADA}

La reinvención de las disciplinas artísticas por parte del bando nacional durante la guerra permanecía en consonancia con la ideología que este pretendía imponer, lo que implicó una nueva forma y uso de la danza. Los géneros que se interpretaban en estas celebraciones "mostradas" carecían de ese carácter ecléctico e internacional que se había estado fraguando durante la República y terminaron sucumbiendo ante un evidente y consciente anquilosamiento que perduraría mucho más allá del conflicto bélico. La difusión del folclore acorde con la estética contemporánea europea desarrollado en el periodo republicano se transformó, a partir de entonces, en la transmisión de un folclore rancio excluido de todo tipo de influencia externa y manipulado según los moldes establecidos como indispensables tanto para cimentar con contenido ideológico y signos representativos el nuevo régimen que se auguraba tras el alzamiento militar como para reafirmar la negación del sistema político anterior.

La intención de instaurar una nueva ideología que reforzara a España como una nueva patria y nación condujo al bando sublevado a utilizar la danza española como una de las fórmulas para lograr esa pretendida identidad del pueblo español. Esta forma de expresión tan particular se tomó como una herramienta más de propaganda durante la cruenta batalla dispuesta a manipular las mentes ciudadanas mediante su tergiversación y formó parte de la "cultura de guerra" (Sevillano 2003, 226), basada en la propagación de una serie de valores, 
intentos. Entre ellos, la acción frustrada por parte del ministro de Instrucción Pública en 1937 de establecer una escuela de danzantes destinada a acoger entre 100000 y 150000 artistas para los diversos actos propagandísticos republicanos, la cual nunca se llevaría a cabo (Mariano 1937, 3). Con esta escuela, se pretendía imitar el engranaje perfecto que el bando contrario había logrado establecer en torno a la acción de la danza como herramienta propagandística de primer orden. Sin embargo, el proyecto frustrado de la escuela de danzantes republicana, o bien por falta de concreción organizativa, o bien por la acelerada pérdida de posiciones durante el conflicto, derivó en la utilización y representación de una danza folclórica espontánea interpretada por el pueblo para nada comparable, por ejemplo, con las masas femeninas encargadas de ejecutar disciplinadamente los manipulados bailes folclóricos.

En el caso de Sevilla, siempre que se pretendía dar una imagen hacia el exterior durante las visitas de autoridades extranjeras o en los actos en honor de países aliados en los teatros de la capital, preponderaba el uso del flamenco, ${ }^{2}$ arte genuino español que los sublevados pretendían exportar. La situación variaba cuando se perseguía mostrar una patria unida a todos los españoles en las concentraciones multitudinarias celebradas en la ciudad. Para este tipo de eventos, se ensalzaba la danza regional, siempre a cargo de la Sección Femenina. En definitiva, el flamenco, secundado, en ocasiones, por la escuela bolera y la danza estilizada, se utilizaba primordialmente como medio de propaganda internacional y la danza regional se limitaba a un uso nacional ${ }^{3}$ que contribuyó, como así afirma Martínez del Fresno $(2012$, 229), a la construcción de un modelo de nación impuesto por el régimen de Franco; los primeros estilos para convencer a las autoridades foráneas del poder y la riqueza de nuestro país y el segundo para afianzar ese sentimiento patriótico de igualdad que se estaba forjando en la mentalidad del pueblo.

No hay que obviar, sin embargo, otras tendencias que, en menor medida, convivieron con las mencionadas en los teatros hispalenses de la mano del bailarín de claqué Bro y los bailarines de salón Hermanos Alfskens, de los bailes de fantasía de Leonor y Gurri o de los mismos ciudadanos cuando llevaban a cabo los bailes de sociedad en diversos escenarios emblemáticos de la ciudad como el Andalucía Palace o las Bodegas Cristina.

Desde un punto de vista general, la danza se feminizó y otorgó a la mujer un rol fundamental en la escena, pero siempre bajo supervisión masculina. Las solistas aparecidas en los ámbitos teatrales y festeros eran sometidas al control y a la censura de las autoridades y actuaban la mayor parte de las ocasiones con un sentido patriótico o de servicio a la nación. El papel del hombre artista en estos entornos se vislumbraba en la manera de representaciones en las que intervenían puntualmente bailaores como Rafael Ortega y el Tumba de Triana, bailarines de diferentes estilos como Bro y los Hermanos Alfskens o los maestros Quiñones, Realito y Otero. El papel de "maestro" siempre era atribuido a la figura masculina, apareciendo en estos casos las artistas como sumisas componentes del cuerpo de baile.

Sin embargo, estas colaboraciones varoniles se limitaban únicamente a los citados ámbitos, ya que, en las concentraciones multitudinarias u otros actos señalados donde la danza regional era pieza clave de la programación, existía una verdadera exclusión masculina y un ferviente protagonismo femenino, siempre bajo ese condicionante viril. A este estilo de danza se le atribuyó un doble servicio: por una parte, suponía un elemento de unión del pueblo y formación de la nueva patria, que la dotaba por este motivo de una fuerte carga simbólica (Martínez del Fresno 2012, 231); por otra, fue una forma indirecta de controlar e instaurar el modelo femenino que se pretendía establecer, otorgando a la mujer un papel imprescindible en la transmisión del folclore a través de un protagonismo "guiado y fingido", es decir, 
imponiéndole el tipo de danzas que debía mostrar y aprender tras ser depuradas, cubiertas de censura y cargadas de elementos artificiosos sin dejar espacio a la nueva creación o diversidad de estilos. De esta forma, las ejecutantes se convertían en simples reproductoras de un cliché acorde con la imagen que se ambicionaba instaurar, es decir, dependientes a través de danzas colectivas, asexuadas con la consecuente exclusión masculina y utilización de trajes sin formas y sumisas al limitar su propagación a lo que la censura establecía como válido en las ocasiones en que las autoridades necesitaban de sus servicios. ${ }^{4}$

\section{FIESTAS}

El estudio de Langa Nuño (2000) sobre las fiestas llevadas a cabo en Sevilla durante la guerra civil resulta esencial para visualizar la manera en la que su organización y desarrollo variaba de acuerdo con la coyuntura política que se iba presentando a lo largo del conflicto. Por una parte, todo acto festivo, fuera o no religioso, en el que se atisbara sospecha de relajación moral o desviación de la solemnidad que merecía el momento (curiosamente, en todos ellos la danza adquiría gran protagonismo), era radicalmente abolido y sustituido por actividades alternativas. Tal caso lo encontramos en la celebración de un rosario público y una solemne función religiosa de penitencia y rogativa "en atención a las gloriosas circunstancias por las que atraviesa nuestra Patria", con la correspondiente destinación del importe de los gastos ahorrados al general Queipo de Llano en lugar de la romería de El Rocío (Archivo Municipal 1937c). Como es bien sabido, esta festividad, plagada de fervor religioso, consta de cierto matiz pagano en cuanto a la realización de bailes, cantes y diversión. Otra de las tradiciones claramente perjudicadas y eliminadas durante la guerra por su identificación con el bando republicano fue la de carnaval, al considerarse "escasa de arte como pródiga en ordinarieces" (ABC, 2 de marzo de 1938). En 1937, la prensa hacía un llamamiento ciudadano en cuanto a su suspensión para centrarse, sin embargo, en una tarea prioritaria para conseguir el éxito de la lucha por la patria: el recibimiento y agasajo de estudiantes portugueses que se encontraban en la ciudad ( $A B C, 9$ de febrero de 1937).

De igual forma, se suprimieron otras fiestas atendiendo, exclusivamente, a las razones de unidad y esfuerzo patriótico, como la sustitución de la feria de abril de 1937 por la Feria de Ganados (Archivo Municipal 1937b) o la Feria de San Miguel en 1936 por la Fiesta de la Raza:

\footnotetext{
Puesta toda la atención de nuestra ciudad en la magna y patriótica empresa de la reconstitución y solución de España, en estos instantes solemnes y definitivos, otro cualquier empeño, aunque lo motive una causa tradicional, resultaría inoportuno y sin eficacia. Esto sucede con nuestra típica Feria de San Miguel, cuya fecha del 28 al 30 de septiembre, coincide con estos días de fervorosos anhelos en que se cifran todas las fuerzas para alcanzar la gloria de libertar a nuestra idolatrada Patria de la oprobiosa esclavitud de los incalificables marxistas, deshonra y ludibrio de nuestro pueblo y nuestra civilización. (Archivo Municipal 1936b)
}

Por otra parte, se recuperaron las fiestas de carácter estrictamente religioso que habían sido abolidas por la República. Estas eran celebradas con gran solemnidad bajo la coordinación de Iglesia, Estado y Ejército y resultaron esenciales en la implantación de una ansiada moral ultracatólica. Por un lado, el Estado daba a la Iglesia libertad y apoyo a la 
hora de retomar su poder sobre el pueblo. Por otro, la Iglesia avalaba esta guerra, hecho que producía un descanso en las posibles malas conciencias de los ciudadanos y, a su vez, servía de plataforma para que los nacionales siguieran adelante con el conflicto bélico con más adeptos cada día. Los principales ejemplos, la Semana Santa, el Corpus, la Inmaculada y diferentes festividades patronales. Con referencia a la presencia de la danza en estos actos, que es el tema que nos ocupa, se ha podido recuperar información acerca de los ensayos y de la participación de los niños seises catedralicios tanto en el Corpus como en la Inmaculada (El Correo de Andalucía, 24 de noviembre de 1938), e incluso, en el caso de Granada, del anuncio de un concurso de zambras gitanas y verbenas como parte de las actividades planificadas para su celebración (El Correo de Andalucía, 25 de mayo de 1937). Con respecto a las fiestas patronales, la rutina establecida se limitaba al desarrollo de diferentes actos religiosos llevados a cabo en la catedral y en otros recintos santificados. Sin embargo, a pesar de que pueda resultar extraña la extensión de estas celebraciones a los teatros de la ciudad, hay que añadir que durante el transcurso de la guerra se encuentran ciertos ejemplos de este tipo, como el Día de la Virgen de los Reyes, anteriormente citada, donde se pudo saborear un programa en el que se ejecutaron diversos números de danza a cargo de los bailes de fantasía de la pareja Leonor y Gurri y la bailarina clásica Mercedes Dalmau (ABC, 14 de agosto de 1936).

\section{VISITAS DE AUTORIDADES}

Desde el inicio de la batalla, Sevilla se marcó como destino turístico preferente y fue anfitriona de diversas autoridades y personalidades que acudían a España bajo los más variados fines políticos. Estas visitas se produjeron durante todo el periodo bélico. No obstante, en 1938, coincidiendo con la formación del Primer Gobierno de Franco, se registró un incremento de estas; el caudillo ya podía ejercer como verdadero anfitrión desde su nueva posición.

En el caso sevillano, las autoridades que acogían a los huéspedes solían ser el general Queipo de Llano, el gobernador civil o el alcalde de la ciudad, los cuales invirtieron, como se ha detallado, todos sus esfuerzos en contentar a los países aliados y desplegar hacia ellos una imagen de poder y grandeza. Para ello, acogían a las comitivas diplomáticas con la mayor pompa posible no escatimando en gasto alguno. También tomaban parte en estas citas celebridades nacionales de rango militar o civil que, por uno u otro motivo, se establecían en Sevilla durante un corto de tiempo.

En cuanto a las modalidades dancísticas, entre 1936 y 1937, la flamenca formaba parte de la mayoría ${ }^{5}$ de las representaciones que se ofrecían a estos ilustres ciudadanos como un elemento más de propaganda. Para tal fin, se contrataban artistas que amenizaban tanto las veladas públicas como las privadas, contando entre los protagonistas más asiduos de estas los cuadros andaluces de los maestros Otero y Realito.

La primera visita bélica la podemos encontrar los días 11, 12 y 13 de octubre de 1936. El gran visir Sidi Hamed El Ganmid, El Majzen, caídes y moros notables del protectorado español de Marruecos disfrutaron de la ciudad coincidiendo con la celebración del Día de la Raza, motivo por el cual se celebraba una fiesta luso-hispano-americana. Tales mandatarios, además de visitar enclaves emblemáticos de la ciudad como la Universidad o el Palacio de la Condesa de Lebrija, pudieron presenciar la grandeza de, digamos, la fiesta más patriótica 
Ortega y los cantaores Manuel Vallejo y Antonio Mairena. En la parte estrictamente musical, se contó con la colaboración de la Orquesta Bética de Cámara, la Banda Municipal y la Banda Jalifana (Archivo Municipal 1936b). Al día siguiente, se deleitaron con la compañía de Carmen Díaz, que llevaba a escena Cuando las Cortes de Cádiz, de Pemán, y en la última jornada acudieron a un gran festival luso-hispano en la Plaza de Toros, en el que compartieron escenario elementos de música, bailes y cantes populares de las dos naciones hermanas y cuyos ingresos estaban destinados a Cocinas Económicas. Como despedida, asistieron a una fiesta privada en la finca Quintillo del Marqués de Soto Hermoso, donde el alcalde acogió a sus invitados de honor con una fiesta campera en la que, con toda seguridad, los huéspedes volvieron a ser agasajados con los bailes típicos de la tierra.

En 1937, encontramos con más frecuencia estancias de personajes célebres en Sevilla, como las visitas de católicos belgas, José Maria Eça de Queirós, subjefe de Prensa de Portugal, legionarios italianos y los parlamentarios ingleses Mr. Mitchell y Mr. Keeling. Sin embargo, refiriéndonos a la participación del aspecto coreográfico, conviene destacar las visitas de estudiantes portugueses y del Sultán Azul.

En febrero de este mismo año, se abría un expediente por parte de la alcaldía que hacía alusión a la llegada de una expedición de estudiantes portugueses, patrocinada por Rádio Club Português con el capitán Botelho al mando. Esta comitiva era exportadora de donativos destinados, exclusivamente, al Ejército del Sur, motivo suficiente para hacer más incipiente el trato que le correspondía. Con este fin, se emitió una carta de bienvenida de Carranza, el entonces alcalde, pidiendo encarecidamente que se agasajara "con el mayor entusiasmo a los demás representantes de la expedición" y dando aviso al rector para que movilizara a los jóvenes universitarios con el fin de acompañar a sus homónimos lusos durante su aventura sevillana (Archivo Municipal 1937a). Ejemplo del agradecimiento que la ciudad mostraba a sus visitantes lo encontramos en esta carta del delegado de Festejos con referencia a la estancia de los estudiantes portugueses en 1937:

¿Y Sevilla, espejo de ciudades hidalgas y agradecidas, que habrá de honrarse con la visita de tan insignes como preclaros representantes del país vecino, que tan claras muestras viene dando de afecto y devoción a nuestra patria, habría de permanecer indiferente ante tan señalado acontecimiento? De manera ninguna. Ella sabrá corresponder a tan efusivas demostraciones con toda su gratitud. (Archivo Municipal 1937a)

El 7 de febrero se les ofreció un acto en la Universidad donde concurrieron dos bellas señoritas bailando en el patio central (El Correo de Andalucía, 8 de febrero de 1937) y se llevó a cabo un recital en un teatro de la ciudad a beneficio del Ejército español en el que participó un Orfeón de estudiantes portugueses y una orquesta excéntrica interpretando canciones portuguesas con su correspondiente fin de fiesta. Como colofón, una fiesta andaluza ofrecida en el Andalucía Palace (figura 1). 


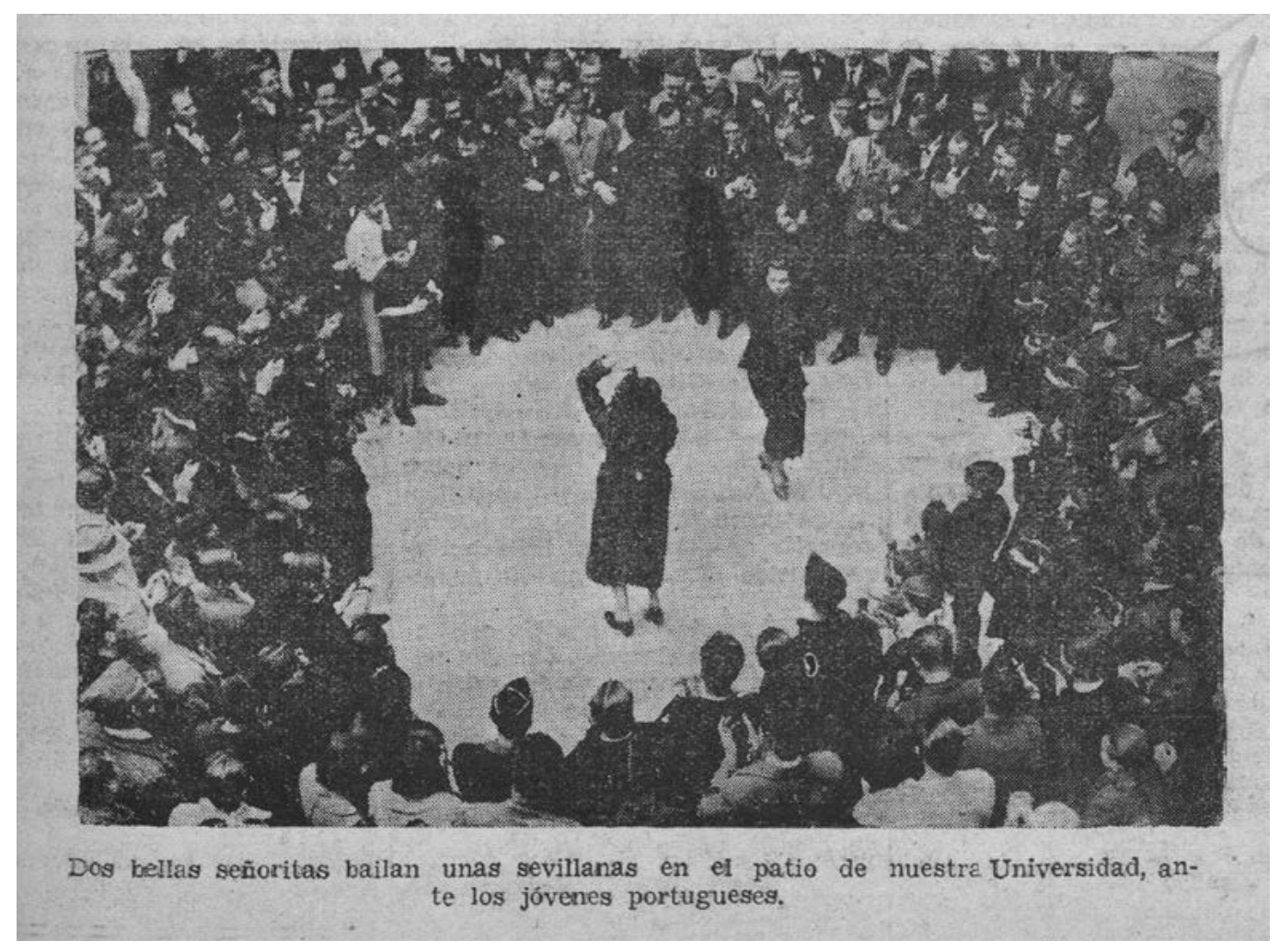

Figura 1. Dos bellas señoritas bailando en el patio central ante la visita de los portugueses Fuente: El Correo de Andalucía (8 de febrero de 1937).

Otra de las estancias se produjo durante agosto, y fue la del Sultán Azul en su trayecto hacia Salamanca, donde, como en apartados anteriores hemos podido comprobar, no se escatimó a la hora de aprobar un presupuesto de 20000 pesetas. El alcalde accidental, Joaquín Gonzalo Garrido, propuso a la Comisión Gestora con respecto al señor del desierto Sidi Mohamed Mostafá Moraboo y su séquito "ser declarados huéspedes de honor de la ciudad" (Archivo Municipal 1937d). Entre los actos que se llevaron a cabo, figura la invitación a las instalaciones del Hospital Militar musulmán instalado en los locales de las Escuelas de la Barzola, en el que se entregó un obsequio a los soldados hospitalizados. Pero de acuerdo con las principales líneas de este estudio, prima la actuación del 25 de agosto en los Jardines del Alcázar de una orquesta y un cuadro andaluz, de los que se ignoran los honorarios percibidos por los artistas. Sin embargo, sí se ha podido rescatar una factura fechada el 17 de septiembre y dirigida al Ayuntamiento de Sevilla del taxi que realizó el traslado de esta compañía a este escenario, que ascendía a un total de 56 pesetas (Archivo Municipal 1937d).

En 1938, de forma simultánea a la creciente autoridad de la FET de las JONS en cuestión de organizaciones festivo-propagandísticas, tuvo una mayor presencia en este tipo de visitas la danza regional de la mano de las flechas de la Sección Femenina. La danza, ante esta nueva incorporación, sufría una evidente desprofesionalización, ya que hasta el momento los espectáculos que se ofrecían estaban a cargo de verdaderos profesionales, muy al contrario de las niñas o mujeres que ejecutaban estos bailes folclóricos. Esta nueva adhesión pudo, en cierta manera, ser un caso puntual al coincidir con la concentración multitudinaria del 29 de octubre, en la que este colectivo participó en la modalidad de bailes regionales. Los meses anteriores a este acto Sevilla fue recibiendo visitas de altos mandos de otros países y de España 
relacionados con las juventudes fascistas bajo la excusa de supervisar los preparativos de este gran evento. Entre ellas, merece destacar la visita de Carmen Werner en dos ocasiones, en las que pudo presenciar, por una parte, un espectáculo donde cien flechas femeninas le mostraron ejercicios gimnásticos y bailes por parejas. Por otra, los ensayos de flechas femeninas en los que se ejecutaron bulerías y sevillanas bajo la supervisión del maestro Quiñones y los bailes aprendidos en los campamentos femeninos, en los que las niñas mostraban preferencia por los de otras regiones siendo especialmente destacada la predilección de las asturianas por el baile de las sevillanas ( $A B C, 27$ de octubre de 1938). En esa misma época, Juta Roetiger, ${ }^{6}$ jefa nacional de las Juventudes Hitlerianas, también tuvo oportunidad de asistir al mismo tipo de exhibiciones ( $A B C, 19$ de octubre de 1938). Independiente de estas muestras coreográficas surgidas, como hemos citado, a raíz de la Demostración Juvenil, se efectuó otra representación de bailarinas "accidentales" durante la llegada de las niñas del Tenin de Sidi lamani (Marruecos español) durante su visita a la España liberada, donde tres parejas de flechas femeninas bailaron sevillanas ante el asombro de las jóvenes homenajeadas (Archivo Municipal 1938c; $A B C, 27$ de agosto de 1938; $A B C, 28$ de agosto de 1938).

Paralelamente a estas actuaciones puntuales "regionales", se iban desarrollando las mismas prácticas profesionalizadoras ejercidas antaño. Ejemplo de ello lo encontramos en abril, con motivo de la llegada a Sevilla de cuatro altos jerarcas del Fascio italiano, a los que el general Queipo de Llano ofreció un lunch y una cena en una venta típica amenizada con su baile correspondiente (Archivo Municipal 1938a); o en mayo, con la visita de oficiales portugueses, los cuales pudieron presenciar en el Teatro San Fernando un espectáculo a beneficio de los gitanos en el que tomaron parte la bailaora Custodia Romero y el bailaor Rafael Ortega que interpretaron unas selectas danzas calés junto con la cantaora gitana Pepita Molina ( $A B C, 18$ de mayo de 1938). No obstante, de la estancia que más documentación se conserva es de la de los Guardias Marinas y alumnos de la Escuela Naval, a los que se les brindó el 29 de mayo, en los Jardines del Alcázar, una actuación de la Orquesta Bética

de Cámara dirigida por José Cubiles y del cuadro andaluz del maestro Otero, que ejecutó su labor durante el descanso y el final del concierto. El presupuesto destinado a este cuerpo de baile, compuesto por doce señoritas, tres músicos y el profesor, ascendió a 300 pesetas y 52 pesetas para el alquiler de coches:

Como está anunciado, a las diez y media de la noche del domingo día 29, tendrá lugar en los jardines del Alcázar, artísticamente exornados y con profusa iluminación, un concierto por la Orquesta Bética de Cámara, dirigida por el eminente pianista Don José Cubiles, actuando también el cuadro artístico del Maestro Otero. La entrada será por la puerta del Patio de Banderas. (Archivo Municipal 1938b)

\section{CELEBRACIONES EN HONOR DE LOS PAÍSES ALIADOS}

Desde el inicio del periodo bélico, se produjeron, de manera asidua, exhibiciones destinadas a rendir homenaje a las naciones amigas, sobre todo durante 1937, año decisivo para Franco en su empeño por ocupar definitivamente el Gobierno de España a costa de una emprendedora búsqueda de alianzas. Tenían lugar en los principales teatros de la ciudad, ocupando entre ellos lugares preponderantes el Coliseo de España y el Teatro Cervantes, 
a los que habitualmente asistía el cuerpo diplomático residente en la capital. En repetidas ocasiones, Sevilla hacía suyas las festividades propias de cada país, mostrando gran respeto, aperturismo y admiración hacia sus costumbres. La danza era elemento indispensable en estas representaciones, que incluían bailes tradicionales de los países homenajeados y actuaciones de renombrados artistas sevillanos. Ejemplos de ello los encontramos en 1937 con la Fiesta Nacional del Trabajador Alemán, celebrada en el Coliseo de España con la asistencia de los cónsules de Alemania, Italia y Portugal. En ella, el señor Fiesler ofreció un discurso de corte fascista ensalzando, por una parte, a Hitler y, por otra, la expulsión de los judíos por los Reyes Católicos. Como fin de fiesta, los niños del colegio alemán ejecutaron bailes y cantes típicos de este país. Otras escenas similares se ofrecieron en este mismo año durante el homenaje a Italia organizado por la FET con la intervención del cuadro flamenco del maestro Realito ( $A B C, 2$ de mayo de 1937) o el homenaje a las naciones amigas ofrecido por el general Queipo de Llano ( $A B C, 28$ de diciembre de 1937).

Ya en 1938, se conmemoró en el Pabellón de Portugal el doce aniversario de la fundación del Estado Nuevo ( $A B C, 31$ de mayo de 1938) y, entrados en la recta final de la contienda, se llevó a cabo la fiesta de la Befana en la Casa del Fascio italiano $(A B C, 12$ de enero de 1939). Pero, sin duda, las celebraciones más populares y continuadas fueron las que tenían como escenario el Hospital Musulmán de La Barzola, convertido en el marco principal de numerosos agasajos y escenas de patriotismo hasta el fin de la guerra. La fiesta del Ramadán, por ejemplo, se festejó tanto en 1937 como en 1938 entre vítores a Franco y a Muley Hassan con la participación de las bandas musicales y la interpretación de cantos y bailes de ambos países, siendo el más popular de España las sevillanas: "Distinguidas señoritas enfermeras, ataviadas a la andaluza, bailaron sevillanas, uniéndose a la fiesta las demás muchachas que vestían toca" (ABC, 7 de diciembre de 1937).

\section{FESTIVALES BENÉFICOS}

La celebración de festivales benéficos en los teatros de Sevilla fue muy común a lo largo de la guerra civil. A través de ellos se pretendía recaudar fondos para diversas causas sociales y acallar los posibles descontentos desembocados a causa de la tensión del momento. Las autoridades nacionales eran conscientes de haberse convertido en el detonante de una guerra injustificada que había ocasionado enormes carencias al pueblo y el objetivo de estos eventos consistía en paliar estas de la manera más festiva. La doble moralidad que se desprende de estos actos sociales se puede comprobar realizando un exhaustivo análisis en torno a las víctimas a las que se rendía homenaje: unos niños huérfanos que no lo serían si el conflicto no se hubiera llevado a cabo, unas familias obreras damnificadas tras el ataque y la destrucción de sus barrios, unas clases menesterosas que estaban sufriendo las consecuencias bélicas y un ejército combatiente cuyos soldados no hubieran asistido a esas terribles y dantescas escenas de no haberse producido el golpe de Estado.

La danza que se ofrecía como medio de diversión la interpretaban profesionales locales de alto nivel, como Mercedes Dalmau y Leonor y Gurri en el caso de las familias damnificadas de los barrios de Triana y San Julián $(A B C, 16$ de agosto de 1936; Carmen Jiménez, Cari Abad, Rafael Ortega y La Macarrona en el homenaje al Alcázar de Toledo ( $A B C$, 10 de octubre de 1936); el cuadro flamenco de La Malena, Al Keus y Carmelita Cruz en el homenaje a los 
pelayos pobres ( $A B C, 22$ de enero de 1937); Eloísa Albéniz y Pastora en el Descanso del Soldado ( $A B C, 25$ de febrero de 1937); las Hermanas Jara en la función para los heridos del hospital ( $A B C, 16$ de junio de 1938); y el Tumba de Triana en un evento patrocinado por el general Queipo ( $A B C, 6$ de noviembre de 1938). Estas figuras actuaban sin ningún tipo de remuneración económica y habían sido llamadas a prestar sus servicios a la patria a través de la prensa días posteriores al inicio de la contienda: "para que presten su concurso a dar el mayor realce a la fiesta" ( $A B C, 4$ de agosto de 1936).

También existían otros y otras artistas nacionales que se ofrecieron voluntariamente. De ello dio noticia la prensa, como es el caso de Imperio Argentina y Rafael Rivelles en su "cooperación generosa" en la función a beneficio del soldado ( $A B C, 8$ de octubre de 1937), Miguel Fleta para el Auxilio Social ( $A B C$, 2 de abril de 193716) o Manuel Ligero ( $A B C, 3$ de noviembre de 1938). En el aspecto coreográfico, la bailaora Custodia Romero formó parte en dos ocasiones de este tipo de espectáculos en 1938, siendo descrita como "adicta al Corazón de la Cruzada" y "trabajadora para varias finalidades patrióticas" ( $A B C, 10$ de agosto de 1938).

En cierta medida, resultaba una forma muy barata de aplacar los ánimos del pueblo. Funciones de primera en las que, gracias a la labor altruista de artistas y el dinero recaudado de las entradas, las autoridades nacionales podían presumir de su extensa labor social sin coste alguno y, de esta forma, poder disponer del verdadero fondo económico para realizar los eventos considerados realmente importantes y necesarios para la victoria final, es decir, las visitas de las autoridades y las celebraciones en honor de países amigos.

Dignas de mención resultan las repetidas acciones destinadas al beneficio del soldado con diferentes motivos: recaudación para el ejército salvador, confección de abrigos para el combatiente y lecturas para el soldado. Dentro de ellas, la más significativa por su extensión temporal (desde enero a octubre de 1937, fecha en la que aparece la última actuación para tal fin) fueron las veladas organizadas con motivo del Descanso del Soldado que se celebraban cada jueves y cada sábado en la Plaza de América e incluía almuerzo con orquesta de bailables. Artistas como los Hermanos Alfskens, Rafael Ortega, Pastora y Eloísa Albéniz, Imperio Argentina, Custodia Romero, Mary del Río y el claquetista Bro difundieron su arte para esta causa. Y razón de ser tenía que los mejores pisaran las tablas de ese escenario si se tiene en cuenta que la verdadera victimización de esta guerra recayó sobre el combatiente amateur expuesto a perder su vida en las trincheras. Unas existencias que jamás tendrían que haberse ofrecido a una causa sin sentido y cuyo fin era acumular el poder de unos mandatarios sin escrúpulos, los mismos que primeramente les ofrecían diversión y espectáculos con la intención solapada de, pocos días más tarde, volver a conducirlos al campo de batalla.

\section{CONCENTRACIONES MULTITUDINARIAS}

A partir de 1938 se implantó el verdadero engranaje propagandístico que la FET llevaría a cabo durante los meses de la guerra y la posguerra, tras lo cual se establecieron los vehículos que formarían parte de este. Una de las acciones que el partido desarrolló fue la organización de concentraciones multitudinarias similares a las de los países fascistas, llegándose a celebrar dos en Sevilla durante este periodo: una de carácter provincial y otra de carácter nacional. Las danzas regionales formaron parte de la Concentración Nacional del 29 de octubre de las Organizaciones Juveniles al suponer un fuerte bastión de poder por la 
"unidad y camadería que procuraban" ( $A B C, 27$ de septiembre de 1938). Por este motivo, se afianzó y se secuenció su enseñanza a través de cursillos, escuelas y campamentos de verano, adquiriendo de esa forma la FET, a través de la SF, otro papel alternativo al meramente propagandístico: el de asumir las tareas de enseñanza y formación, de las cuales, en el caso concreto de Sevilla, se han encontrado referencias respecto de cursillos de cultura nacional sindicalista y enseñanza de folclore y bailes regionales impartidos por las camaradas Guadalupe Pin y Ángela Mariutti ( $A B C, 24$ de noviembre de 1938; $A B C, 26$ de noviembre de 1938). A partir de este momento, el rol profesionalizador de la danza se complementó con otro tipo de rol más amateur, en el que artistas improvisadas adquirirían la responsabilidad de la ejecución de los bailes propios de cada región.

Estas concentraciones estaban destinadas, por una parte, a la recuperación de la ilusión de un pueblo castigado por las atroces circunstancias, pues su asistencia masiva procuraba un estado de plenitud derivado de la pertinencia a aquella "nueva comunidad" (Sevillano $2003,234)$ que se estaba formando. Por otra parte, resultaron una forma idónea de mostrar esa pretendida unidad territorial a través de la unión de participantes de diferentes autonomías mediante la ejecución e intercambio, por ejemplo, de bailes propios de su región. ${ }^{7}$ Pero, sin duda, su misión fundamental fue la de engrandecer y encumbrar el poder de Franco, transfigurando simbólicamente su imagen carismática mediante este tipo de discurso, rito y liturgia (Sevillano 2003, 225): miles de afiliados de la FET de las JONS formaban parte activa desfilando y ejecutando sus ejercicios gimnásticos y bélicos disciplinadamente. El caudillo mostraba de esta manera el control de su poder al tener a sus pies a miles de admiradores agasajándolo y mostrando su dedicación a la España nacional. La disciplina con que estos jóvenes flechas y cadetes realizaban sus ejercicios simbolizaba la disciplina que se pretendía extender por todo el país, hecho que no tardaría en llegar tras la finalización de la guerra civil y la imposición de una dictadura que sumergió al país en una época de oscurantismo.

La primera demostración nacional de las Organizaciones Juveniles de Falange Española Tradicionalista y de las Jons ha constituido un verdadero éxito, que sin duda alguna ha sobrepasado a lo que se esperaba. Un éxito de público. Pero, especialmente y es lo que queremos hacer notar, un éxito de las posibilidades del Movimiento, de su capacidad, bien demostrada en este alarde que se ha efectuado por primera vez. ( $A B C, 30$ de octubre de 1938)

En 1938, se abrió paso en Sevilla con un festival gimnástico-deportivo de carácter provincial en la Plaza de Toros de la Maestranza, organizado por la FET, en el que se convocaron a 4000 flechas y cadetes pertenecientes a la organización juvenil sevillana. Insertos en el programa que los 14000 asistentes al acto pudieron presenciar, se encontraban simulacros de combate ofensivo, ejercicios físicos educativos, atletismo y configuración de emblemas y letreros sobre el terreno alusivos al alzamiento. En esta ocasión, el papel de las 400 flechas femeninas participantes se redujo a la exposición de ejercicios de gimnasia rítmica, sin especificar si formaron parte de este número las danzas regionales ( $A B C, 5$ de enero de 1938).

El 29 de octubre de este mismo año, la ciudad, testigo de las principales fiestas celebradas durante la guerra, fue seleccionada por Franco para convertirse en anfitriona del primer acto masivo que tuvo lugar en la España nacional. De esta forma, se consolidaba definitivamente como urbe imprescindible en la muestra de la grandeza de la España que estaba por venir de la mano del futuro régimen franquista. La 1. ${ }^{a}$ Organización Nacional de Organizaciones Juveniles, 
un homenaje a los Caídos por Dios y por España, conmemoraba, a su vez, el V Aniversario de Falange. Su organización se relegó una vez más a la FET de las JONS, aceptando este partido nuevamente ese rol propagandístico asignado en esta nueva etapa gubernamental que incluiría de forma sistemática el homenaje a los caídos y mártires de la guerra como parte del discurso utilizado contra la anti-España (Sevillano 2003, 232) (figura 2).

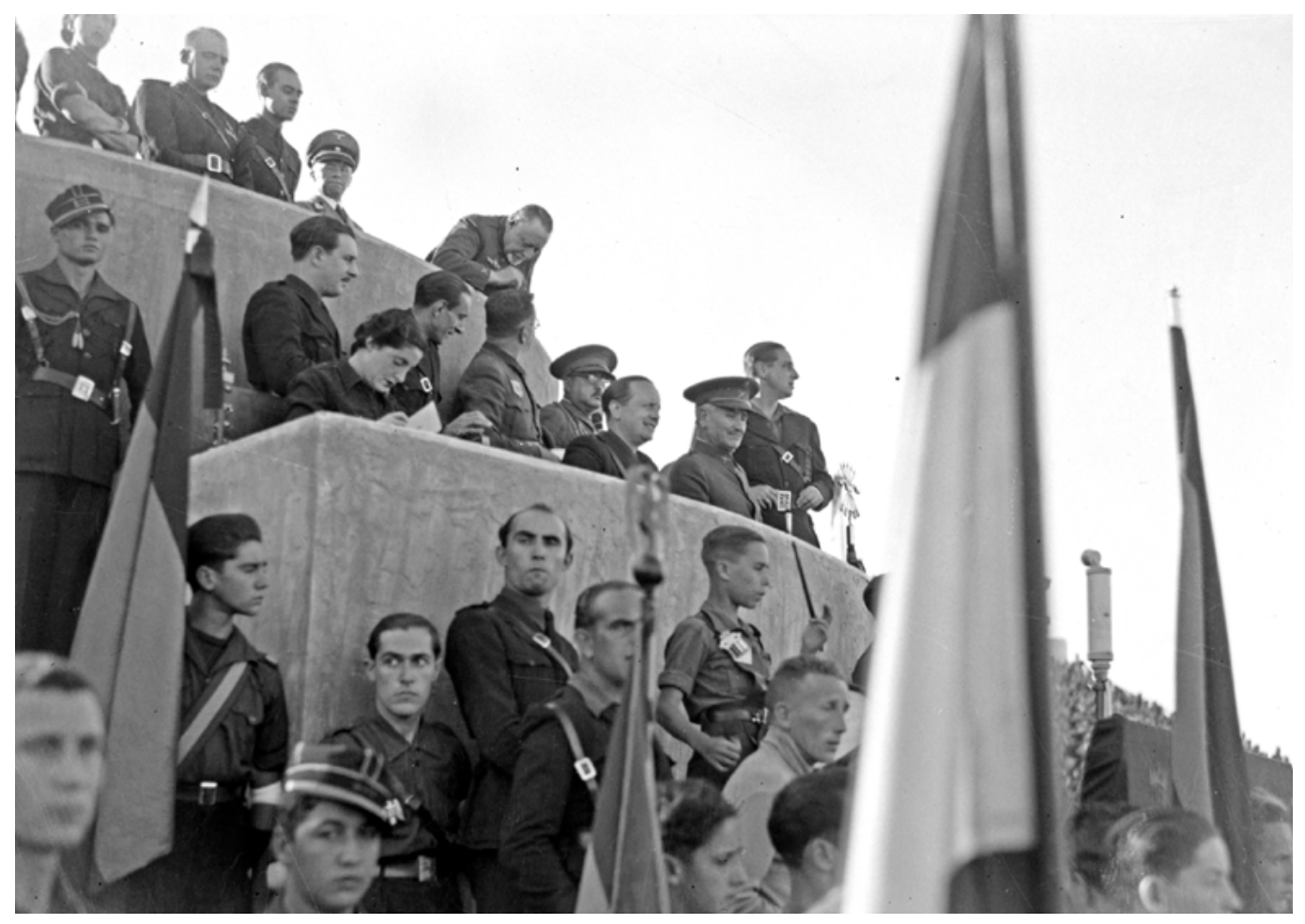

Figura 2. Autoridades asistentes a la Primera Demostración Nacional de las Organizaciones Juveniles (29 de octubre de 1938). Fuente: Fototeca Municipal de Sevilla. Fondo Serrano.

De este único y singular evento se destinaron alusiones y noticias durante todo octubre en las diferentes cabeceras sevillanas y sus respectivos suplementos. Fueron numerosas las visitas de autoridades nacionales y extranjeras con el fin de supervisar la preparación y el desarrollo del acto; además de Juta Roetiger y Pilar Primo de Rivera, fue muy destacada la visita de Sancho Dávila al campamento de flechas masculinas levantado a causa de la lluvia, así como el interés que Carmen Werner mostró durante los ensayos y el hospedaje en hogares sevillanos de las flechas femeninas visitantes. También en estos días previos se celebraron desfiles y fiestas en salas privadas, como la que tuvo lugar en una sala donde las flechas interpretaron bailes regionales, especialmente andaluces, en los que destacó la niña Mimí Azcoitia ( $A B C, 28$ de octubre de 1938). De igual forma, se plasman diariamente noticias sobre las instrucciones dadas por la FET de las JONS a sus afiliados, así como los ensayos que las pequeñas realizaban en sus ciudades de origen antes de su llegada a Sevilla.

En el acto, celebrado en el Stadium y presenciado por millares de personas y gran número de autoridades nacionales, se contó con la participación de 6000 flechas y cadetes de las diferentes provincias españolas. En el programa, se alternaron las secciones de Educación Premilitar con diferentes números de simulacro de combate ofensivo, exhibición de Flechas Navales y Educación Física, donde se incluían danzas regionales, deportes, gimnasia rítmica 
y gimnasia educativa. Para finalizar, de forma idéntica a la anterior concentración celebrada en enero, se llevaron a cabo composiciones sobre el terreno de grandes y variados rótulos y emblemas alusivos al Movimiento, así como canciones regionales, marchas e himnos ( $A B C$, 29 de octubre de 1938) (figura 3).

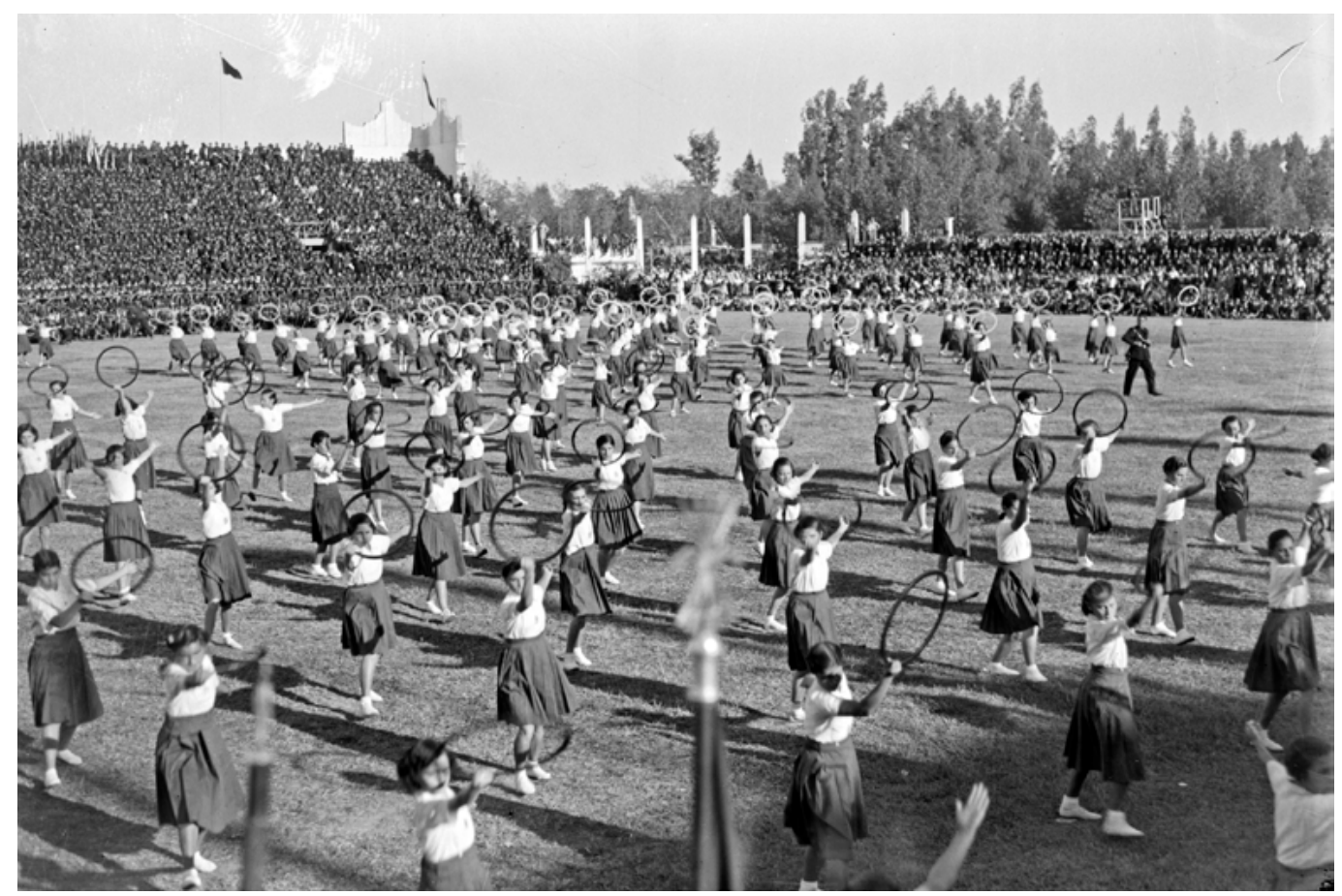

Figura 3. Jóvenes flechas ejecutando ejercicios gimnásticos en el Stadium (29 de octubre de 1938) Fuente: Fototeca Municipal de Sevilla. Fondo Serrano.

El número de danzas regionales fue uno de los más aplaudidos y estuvo a cargo de 200 flechas femeninas representantes de seis regiones, que ejecutaron bailes de sus respectivos lugares de origen. Una muestra más de la gran obra maestra nacional construida a través de la utilización propagandística de la danza:

Sobre un tablado, situado en medio del field, actuaron las flechas castellanas, asturianas, montañesas, andaluzas, etc. Se bailaron jotas, muñeiras, malagueñas, sevillanas y se cantó por asturianas y fandanguillos, entre grandes aplausos del público. Las muchachas estaban vestidas a la usanza de sus respectivas regiones. Indiscutiblemente este fue un número que agradó mucho y que al público sevillano recordó aquellas fiestas inolvidables de Las Regiones en Sevilla, precursoras de la Exposición. ( $A B C, 30$ de octubre de 1938)

\section{CONCLUSIONES}

Sevilla fue una de las escasas capitales que se adhirieron a la causa nacional desde el comienzo de la contienda. Tanto su posición geográfica estratégica y militar como las populares medidas llevadas a cabo por el general Queipo de Llano la convirtieron en todo un referente nacional e internacional del bando franquista. Se puede decir que asumió un 
papel de ciudad piloto donde se llevaron a cabo determinados experimentos, siempre con fin propagandístico, relacionados, por una parte, con el modelo utópico de ciudad nacional que se anhelaba y, por otra, con las reacciones que podía provocar la imposición ideológica del nuevo Estado ante la ciudadanía y el resto de países aliados. De ahí que se eligiera como sede de las más sonadas visitas de comitivas extranjeras, de las principales fiestas nacionales y de las primeras concentraciones multitudinarias.

La predilección del público bélico por las diversas manifestaciones dancísticas fue un aspecto que los sublevados asumieron desde el inicio de la contienda. Se sirvió de ellas a través de su manipulación para contribuir a esa ansiada victoria final. En gran parte de las empresas que en primicia se desarrollaban entre fronteras sevillanas, la actividad coreográfica ocupó un lugar esencial, siempre relegando su cometido a lo oficialmente estipulado para converger de manera directa con la implantación del nuevo régimen.

La danza española como vehículo propagandístico incorporó variadas misiones trazadas con pulcritud y acierto exacerbado. Por una parte, en su estilo flamenco (que incluía puntualmente bailes de escuela bolera y danza estilizada), representado por destacados artistas del momento, se convirtió en símbolo identitario de lo español ante la demostración de poder hacia otras naciones y, por supuesto, hacia los militantes nacionales. Entre las referencias, encontramos constantes alusiones a esta forma de expresión en visitas y recepciones de autoridades extranjeras y nacionales, festivales benéficos y fiestas y homenajes a países aliados.

Sin embargo, hacía falta concretar un segundo nivel de manipulación ciudadana para unificar los ideales e intereses de las diferentes regiones con el propósito de crear una España nueva y única. Para este fin, las autoridades nacionales "recrearon" un género de danza cercano y próximo con el que se identificara el pueblo español. Para ello, debía idearse un modelo del que formara parte activamente y lo asumiera como propio, aun a sabiendas de que esta tarea conllevaba implícitamente una evidente desprofesionalización en la ejecución: la danza regional, representada, principalmente, en concentraciones multitudinarias y en algunos homenajes a países aliados.

La responsabilidad de la mujer en la recolección del repertorio, su enseñanza y ejecución formaba parte de un plan que, minuciosamente supervisado y controlado, se utilizó como parte del engranaje propagandístico llevado a cabo por el caudillo para convencer a los ciudadanos de la necesaria unidad que España añoraba y que le había sido arrebatada durante la República. Este estilo de baile, por tanto, asumió un doble servicio: por una parte, figuró como elemento de unión de la nación y formación de la nueva patria, pero siempre sirviendo como nación-pueblo a la nación-Estado, es decir, reduciendo su participación a los actos menos solemnes y más propagandísticos. Por otra, se convirtió en una forma indirecta de tener el control sobre ese modelo femenino que se pretendía establecer al otorgar a la mujer un papel fundamental en la transmisión del folclore a través de un "protagonismo guiado y fingido", es decir, bajo la imposición de un tipo de danza que debía mostrar y aprender no sin antes haber sido minuciosamente depurado, cubierto de censura y cargado de elementos artificiosos sin dejar espacio a la nueva creación o diversidad de estilos. En este caso, la mujer sevillana se resistió en cierta medida a ejercer el "modelo femenino" implantado y, por ello, sufrió las consecuencias de esta tipología de comportamiento confrontado según las pautas establecidas. Su nula consciencia y sus disipadas costumbres de ocio al bailar determinadas coreografías censurables durante la vida nocturna la condujeron a sufrir acusaciones por parte de las autoridades eclesiásticas. A este respecto, se ha constatado 
la existencia de otro tipo de danza más libertina que se llevaba a cabo en los lugares de ocio nocturno y de recreo. Tan necesaria para la formación de ese pretendido nuevo Estado como la anterior, permaneció, sin embargo, en la sombra más absoluta bajo el influjo de la corriente ultracatólica que dominaba la ciudad y la sumergía en la doble. Sin embargo, volviendo a tratar el asunto bajo el prisma de esa doble moralidad, la dedicación de la mujer a los cometidos sociales atribuidos por las autoridades nacionales para el sexo femenino y el "protagonismo fingido" que mantenía en todos los actos y eventos en los que se solicitaba su intervención a través de las danzas regionales, la llevó a desempeñar un doble papel de mujer sumisa-mujer rebelde muy alejada del estándar de la época.

En cuanto al segundo objetivo planteado, se puede afirmar que la danza desarrollada durante la guerra civil en Sevilla asumió las características posbélicas otorgadas en cuanto a su rol propagandístico dentro del bando nacional y su feminización. En relación con este último término, los condicionantes varoniles a los que era sometida eran similares a los de la danza de posguerra; por una parte, en lo referente a su empleo como símbolo (femenino) de la nación-pueblo que acoge o agasaja a la nación-Estado (masculino) mediante su presencia en barrios de ciudades y calles de pueblos y no en los actos políticos más solemnes pertenecientes al ámbito de este segundo tipo de escenificación varonil (Martínez del Fresno 2012, 231). Por otra, la irreal libertad coreográfica otorgada a la mujer tanto en la danza regional como en el resto de estilos le suponía, nuevamente, un claro sometimiento y una preponderancia masculina sobre la totalidad de sus acciones, hechos que constituyen el discurso político-propagandístico a través de la danza de posguerra como continuación del establecido en la capital andaluza durante la contienda. Sevilla, gracias a su rol de escaparate nacional e internacional, encarnó un destacado protagonismo en cuanto a la definición y concreción de lo que sería la danza bélica española característica del bando franquista, asentando a su vez las bases de la futura danza de posguerra. Tanto durante el conflicto bélico como en años posteriores, la danza como acción sustancialmente femenina permaneció realmente en un segundo plano, a pesar de ser utilizada continuadamente como mecanismo de propaganda. En los actos políticos verdaderamente trascendentales, simplemente se ausentaba de la escena y quedaba relegada a los actos benéficos, festivos y populares. Su utilización era siempre bajo control y supervisión, en momentos y actos determinados por las autoridades, ya que su tradicional conexión con el cuerpo y la sexualidad podía conducir a complicar la narración que se pretendía establecer, podía dirigir el discurso político hacia otra dirección indeseada.

\section{NOTAS}

1 En adelante, AMS.

2 Aunque el repertorio mayoritario del estilo flamenco se componía de bailes de los diferentes palos, en diversas ocasiones incluía danzas pertenecientes a los estilos de escuela bolera y danza estilizada.

3 A partir de agosto de 1938, existe evidencia de dos casos en los que se produjo una utilización de danza regional durante las visitas de comitivas extranjeras: coincidiendo con la preparación de la demostración nacional del 29 de octubre y en una visita de una comitiva de niñas del Marruecos español. Pero son casos puntuales, ya que no volverá a darse el caso durante el conflicto bélico. 
4 El análisis realizado por Martínez del Fresno en torno a la utilización de la danza tradicional en la posguerra como símbolo (femenino) de la nación-pueblo que acoge o agasaja a la nación-Estado (masculino) mediante su presencia en calles y pueblos y no en los actos políticos más solemnes pertenecientes al ámbito de la escenificación de la nación-Estado se puede trasladar a Sevilla durante la guerra civil.

5 También nos encontramos, aunque en un porcentaje muy bajo, la danza regional.

6 La visita a Sevilla de esta autoridad coincide con el tiempo en el que realizó una estancia por algunas provincias de la España nacional. Para más información acerca de las relaciones internacionales de Sección Femenina, véase Martínez del Fresno (2012, 357-406).

7 Mediante la danza regional se fomentó el sentimiento de hermandad entre las diferentes regiones, paliando de alguna forma el vacío de contenido respecto de la falta de intervención en la administración del poder, entonces centralizado y estatalizado, existente entre la Segunda República y los planes de desarrollo de la década de los sesenta (Martínez del Fresno 2012, 247).

\section{REFERENCIAS}

Abella Bermejo, Rafael. 1975. La vida cotidiana durante la Guerra Civil. Barcelona: Planeta.

Casero García, Estrella. 2011. La España que bailó con Franco: coros y danzas de la Sección Femenina. Madrid: Nuevas Estructuras.

Langa Nuño, Concha. 2000. “La formación del franquismo en Sevilla: las fiestas políticas durante la Guerra Civil." Revista de Historia Contemporánea 9 (2): 345-371.

- 2007a. "De republicanos a 'rojos': la imagen de la República en la prensa nacional durante la Guerra Civil (el caso de $A B C$ de Sevilla)." En La comunicación durante la Segunda República y la Guerra Civil, coordinado por Antonio Checa, Carmen Espejo, Concha Langa y Miguel Vázquez, 450-470. Madrid: Fragua.

- 2007b. De cómo se improvisó el franquismo durante la guerra civil: la aportación del ABC de Sevilla. Sevilla: Centro de Estudios Andaluces.

Escolar Sobrino, Hipólito. 1987. La cultura durante la Guerra Civil. Madrid: Alhambra.

Fernández Higuero, Atenea. 2015. "Catalanes en Madrid: la danza tradicional como embajada de la Generalitat en el primer aniversario de la resistencia (noviembre de 1937)". En Danza, educación e investigación: pasado y presente, coordinado por José Luis Chinchilla y Ana María Díaz, 319-333. Archidona: Aljibe.

Iglesias, Iván. 2013. “De 'cruzada' a 'puente de silencios': mito y olvido de la Guerra Civil española en la historiografía musical". Cuadernos de Música Iberoamericana 25-26: 177-188.

Martínez del Fresno, Beatriz. 2010. “La sección femenina de la falange y sus relaciones con los países amigos: música, danza y política exterior durante la Guerra y el primer franquismo (1937-1943)". En Cruces de caminos: intercambios musicales y artísticos en la Europa de la primera mitad del siglo XX, coordinado por Gemma Pérez Zalduondo y María Isabel Cabrera García, 357-406. Granada: Universidad de Granada.

- 2012. "Mujeres, tierra y nación: las danzas de la sección femenina en el mapa político de la España franquista (1939-1952)". En Discursos y prácticas musicales nacionalistas (1900-1970), coordinado por Pilar Ramos López, 229-254. Logroño: Universidad de La Rioja.

- 2013. "La danza en España durante el franquismo". En Música, ciencia y pensamiento en España e Iberoamérica durante el siglo XX, coordinado por Adela Presas y Leticia Sánchez de Andrés, 347385. Madrid: Universidad Autónoma de Madrid.

- 2015. "Una cruzada necesaria: música, danza y tradición nacionalsindicalista (1940-1945)". En Danza, educación e investigación: pasado y presente, coordinado por José Luis Chinchilla y Ana María Díaz, 335-358. Archidona: Ediciones Aljibe. 
Murga Castro, Idoia. 2009. "Escenografía de la danza en la Guerra Civil española". En Arte en tiempos de guerra, coordinado por Miguel Cabañas Bravo, Amelia López-Yarto Elizalde y Wifredo Rincón García, 317-332. Madrid: Consejo Superior de Investigaciones Científicas.

Pérez Zalduondo, Gemma. 2013. "La música en los intercambios culturales entre España y Alemania (1938-1942)". En Formulación, fracaso y despertar de la conciencia crítica en la música española durante el franquismo (1936-1958), coordinado por Gemma Pérez Zalduondo y María Isabel Cabrera García. Sevilla: Libargo.

Pizarroso Quintero, Alejandro. 2002. “La propaganda durante la guerra civil: aproximación al estado de la cuestión". En Del periódico a la sociedad de la información, 352-373. Madrid: Sociedad Estatal España Nuevo Milenio.

Rodríguez Centeno, Juan Carlos. 2003. Anuncios para una guerra: política y vida cotidiana en Sevilla durante la Guerra Civil. Sevilla: Ayuntamiento de Sevilla.

Ruiz Abellán, María Concepción. 1993. Cultura y ocio en una ciudad de retaguardia durante la guerra civil (Murcia, 1936-1939). Murcia: Real Academia Alfonso X el Sabio.

Sevillano Calero, Francisco. 2003. Propaganda y medios de comunicación en el Franquismo. Alicante: Servicio de Publicaciones de la Universidad de Alicante.

- 2014. "La propaganda y la construcción de la cultura de guerra en España durante la Guerra Civil." Studia historica. Historia contemporánea 32: 225-237.

\section{MATERIAL DE ARCHIVO}

Archivo Municipal. Sevilla. Negociado de Ferias y Festejos. 1936a. Expediente instruido con motivo de la celebración de la velada de Triana en el año 1936. Ex1936/24.

- 1936b. Expediente instruido con motivo de la celebración del Día de la Raza de la FET y de las JONS. Ex1936/30.

- 1937a. Expediente instruido con motivo de la visita a esta ciudad de una expedición organizada por estudiantes portugueses, patrocinada por Radio Club portugués, portadora de donativos destinados exclusivamente al ejército Sur. Ex1937/2.

- 1937b. Expediente instruido con motivo de acuerdo de supresión de la Feria de abril, sustituyéndose por Feria de Ganados. Ex1937/10.

- 1937c. Expediente instruido con motivo de la supresión por este año de la Romería del Rocío y celebración de un Rosario público y solemne Función Religiosa de penitencia y rogativa. Ex1937/18.

- 1937d. Expediente instruido con motivo de comisiones de moros notables. Ex1937/26.

- 1937e. Expediente instruido con motivo de resolución de la Secretaría General del Jefe del Estado, relativa al lugar que en los actos oficiales debe ocupar el Jefe Provincial de FET de las JONS. Ex1937/33.

Archivo Municipal. Sevilla. Negociado de Asuntos Especiales. 1938a. Expediente instruido con motivo de visita a Sevilla de comisiones y personalidades diversas. Ex1938/15.

- 1938b. Expediente instruido con motivo de la visita a Sevilla de los Guardias Marinas y alumnos de la escuela naval española. Ex1938/19.

Archivo Municipal. Sevilla. Secretaría General. 1938c. Expediente instruido con motivo de la visita a Sevilla de una comisión de niñas del Tenin de Sidi lamani (Marruecos español). Ex1938/25, D1792. 


\section{MATERIAL HEMEROGRÁFICO}

$A B C, 4$ de agosto de 1936.

- 14 de agosto de 1936.

- 16 de agosto de 1936.

- 10 de octubre de 1936.

- 14 de octubre de 1936.

-2 de enero de 1937.

- 22 de enero de 1937.

- 9 de febrero de 1937.

- 2 de abril de 1937.

- 28 de abril de 1937.

- 2 de mayo de 1937.

— 8 de octubre de 1937.

- 7 de diciembre de 1937.

- 28 de diciembre de 1937.

- 5 de enero de 1938.

- 2 de marzo de 1938.

- 18 de mayo de 1938.

- 31 de mayo de 1938.

- 16 de junio de 1938.

- 10 de agosto de 1938.

- 27 de agosto de 1938.

- 28 de agosto de 1938.

- 27 de septiembre de 1938.

- 19 de octubre de 1938.

- 28 de octubre de 1938.

- 27 de octubre de 1938.

- 29 de octubre de 1938.

- 30 de octubre de 1938.

-3 de noviembre de 1938.

- 6 de noviembre de 1938.

- 24 de noviembre de 1938.

- 26 de noviembre de 1938.

- 11 de enero de 1939.

- 12 de enero de 1939.

El Correo de Andalucía, 8 de febrero de 1937.

- 25 de mayo de 1937.

- 24 de noviembre de 1938.

Mariano, Tomás. "Escuela de danzantes". ABC, 10 de noviembre de 1937. 


\section{Cómo citar:}

Díaz Olaya, Ana María. 2018. "Danza mediatizada al servicio de la ideología en las fiestas y actos propagandísticos celebrados en Sevilla durante la guerra civil española". Cuadernos de Música, Artes Visuales y Artes Escénicas 13 (2): 97-121. http://doi.org/10.11144/javeriana.mavae13-2.dmas 
